\title{
Blunt Traumatic Cervical Spine Fractures in Iran
}

\author{
Soheil Saadat ${ }^{1}$, Aliashraf Eghbali ${ }^{1}$, Alexander R. Vaccaro ${ }^{2}$, Mahdi Sharif-Alhoseini ${ }^{1}$, \\ Vafa Rahimi-Movaghar ${ }^{1,3}$ \\ ${ }^{1}$ Sina Trauma and Surgery Research Center, Tehran University of Medical Sciences, Tehran, Iran \\ ${ }^{2}$ Department of Orthopaedic Surgery, Thomas Jefferson University and Rothman Institute, Philadelphia, USA \\ ${ }^{3}$ Research Centre for Neural Repair, University of Tehran, Tehran, Iran \\ E-mail:v_rahimi@sina.tums.ac.ir
}

Received April 4, 2011; revised August 25, 2011; accepted September 26, 2011

\begin{abstract}
Background: Blunt traumatic cervical spine fractures (TCSF) are serious injuries which may be associated with considerable mortality and morbidity. We describe the epidemiology of blunt traumatic cervical spine fracture in Iran over a definable time period. Methods: in a cross-sectional study, the data including the distribution of TCSF, demographics, mechanisms, abbreviated injury scale (AIS), spinal cord associated injuries and final outcome of patients, was extracted from the Iranian national trauma registry database in target hospitals in eight major cities of Iran from 1999 to 2004. The Chi square test was used to compare mortality and one-way ANOVA was used to compare ISS amongst the categories of TCSF. Results: TCSF was identified in 120 cases, of these $70.8 \%$ were male. Their mean age was $36.6 \pm 17.2$ years. The overall incidence of TCSF among all trauma patients was 0.7\% (95\%CI: 0.61\% - 0.88\%). The TCSF incidence among all spine fractured patients was 19.38\% (95\%CI: $16.34 \%$ - 22.72\%). The most common mechanism of TCSF was a motor vehicle collision (66.7\%). The overall percentage of in-hospital death for TCSF was 12.6\%. There were no statistically significant difference in death and injury severity scores (ISS) among TCSF categories $(p>0.05)$. Spinal cord and root injuries occurred in $34.9 \%$ and $2.4 \%$ of TCSF, respectively. Conclusions: preventive strategies need to be developed in order to reduce the number and severity of TCSF in the general Iranian population.
\end{abstract}

Keywords: Cervical Spine, Fractures, Iran, Motor Vehicle Crash, Trauma

\section{Introduction}

Injuries to the cervical spine are of critical importance given the potential risk of damage to the spinal cord leading to paralysis and life long consequences [1]. Studies of cervical spinal injury report prevalences ranging from $1 \%$ to $14 \%$ [2]. Blunt traumatic cervical spine fractures (TCSF) accounts for $1 \%$ to $3 \%$ of trauma patients $[3,4]$ but the resulting loss of neurologic function, i.e. incomplete/complete quadriplegia following cervical spinal cord injuries are an important source of mortality and morbidity [5]. TCSF is seen in $19.2 \%-20.8 \%$ of blunt traumatic spine fractures [6-8]. It most frequently occurs in male patients [9]. The cervical spine is vulnerable to injuries resulting from high-energy motor vehicle collisions and falls [10]. TCSF can be potentially devastating, with delayed diagnosis and neurologic damage resulting in death and disability [11-13]. Prompt immo- bilization and timely diagnosis are essential for optimal therapy. Delayed, missed, or inaccurate diagnosis can result in life-long devastating implications [14].

Among patients undergoing emergency department cervical spine radiography following blunt trauma, cervical spine injuries were found to be more common among the young male patients $[8,15]$ and the C1 - C2 was the most common location of injury [4].

The Injury severity score (ISS) is an anatomically based ordinal scale, with a range from 1 to 75 . To compute the ISS, the nine abbreviated injury scale (AIS) body regions are grouped into six: head or neck, face, chest, abdominal or pelvic contents, extremities or pelvic girdle, and external. The ISS is then calculated as the sum of the squares of the highest AIS scores for the three most severely injured body regions [16].

So far, there has been no reliable investigation of distribution of TCSF among hospitalized traumatic patients 
in Iran. The purpose of this study is to describe blunt TCSF in traumatic patients admitted to general hospitals in Iran by using a cross-sectional study and to determine the incidence, demographics, etiology, severity, associated injuries and final outcomes.

\section{Methods}

This is a cross-sectional study which was performed using the data from Iran national trauma registry database from August 1999 to February 2004. This data was collected from target hospitals in eight major cities of Iran. Information on every patient who was admitted in these hospitals due to trauma and had a hospital stay of more than 24 hours was registered into the database. The data which was extracted from the original database for this study included patients' general demographic characteristics, mechanism of trauma, levels and regions of spinal injury, associated injuries, AIS, duration of hospital stay, and final disposition/outcome. The type of TCSF and the mechanism of accident were coded according to the International Classification of Diseases, the $10^{\text {th }}$ revision (ICD-10). The region of TCSF was divided by ICD-10 diagnostic codes and classified into C1 (S12.0), C2 (S12.1), C3-7(S12.2) and multiple (S12.7), Concussion and edema of the cervical spine cord (S14.0), Unspeci- fied injury of the cervical spinal cord (S14.1), Injury of the cervical nerve root (14.2), Injury of a peripheral upper extremity nerve (14.4).

The statistical analysis was conducted using SPSS 15.0 (SPSS Inc, Illinois, USA). The Chi square test was used to compare mortality and one way analysis of variance was used to compare ISS amongst the categories of TCSF.

\section{Results}

Of 16,321 enrolled patients, 120 (0.74\%) (95\% CI: $0.61 \%-0.88 \%$ ) had a cervical spine fracture. The overall incidence of TCSF among all spine fractured patients was 19.38\% (95\% CI: 16.34\% - 22.72\%). Enrollment rates in all trauma patients varied by age (Figure 1). The absolute number of TCSF also varied by age and was greatest in young adults (aged 15 to 45 years) and older individuals (aged 60 to 64 years) (Figure 2). The distribution of fractures is listed in Table 1. C2 was the most common site of fracture, accounting for $20.8 \%$ of all fracture, whereas lower cervical spine (C3 to C7) fractures were seen in 65 (54.2\%) patients. The characteristics data are presented in Table 2. The majority of the patients were male (70.8\%). Their mean age was $36.6 \pm$ 17.2 years.

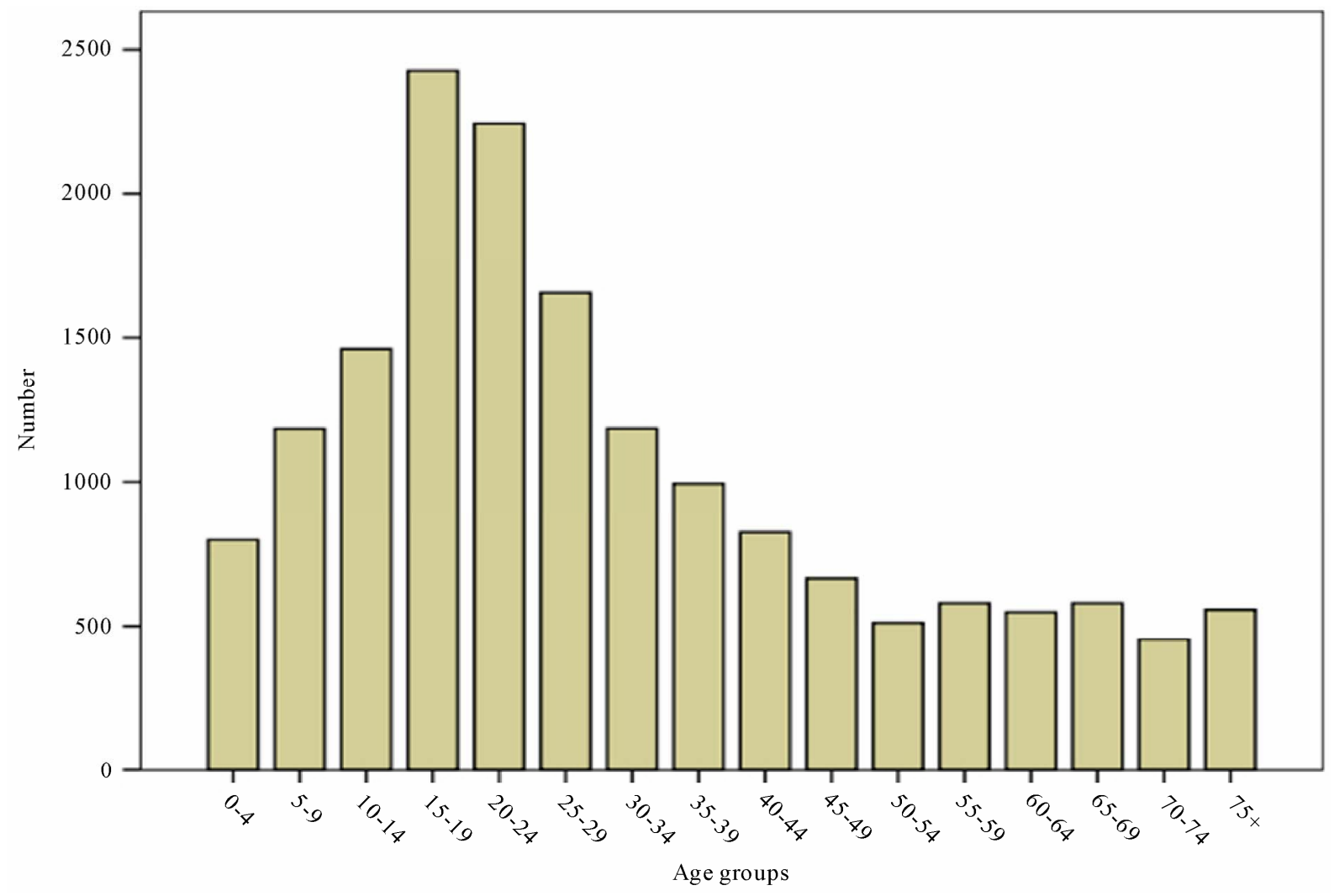

Figure 1. Number of enrolled patients for each age category. 


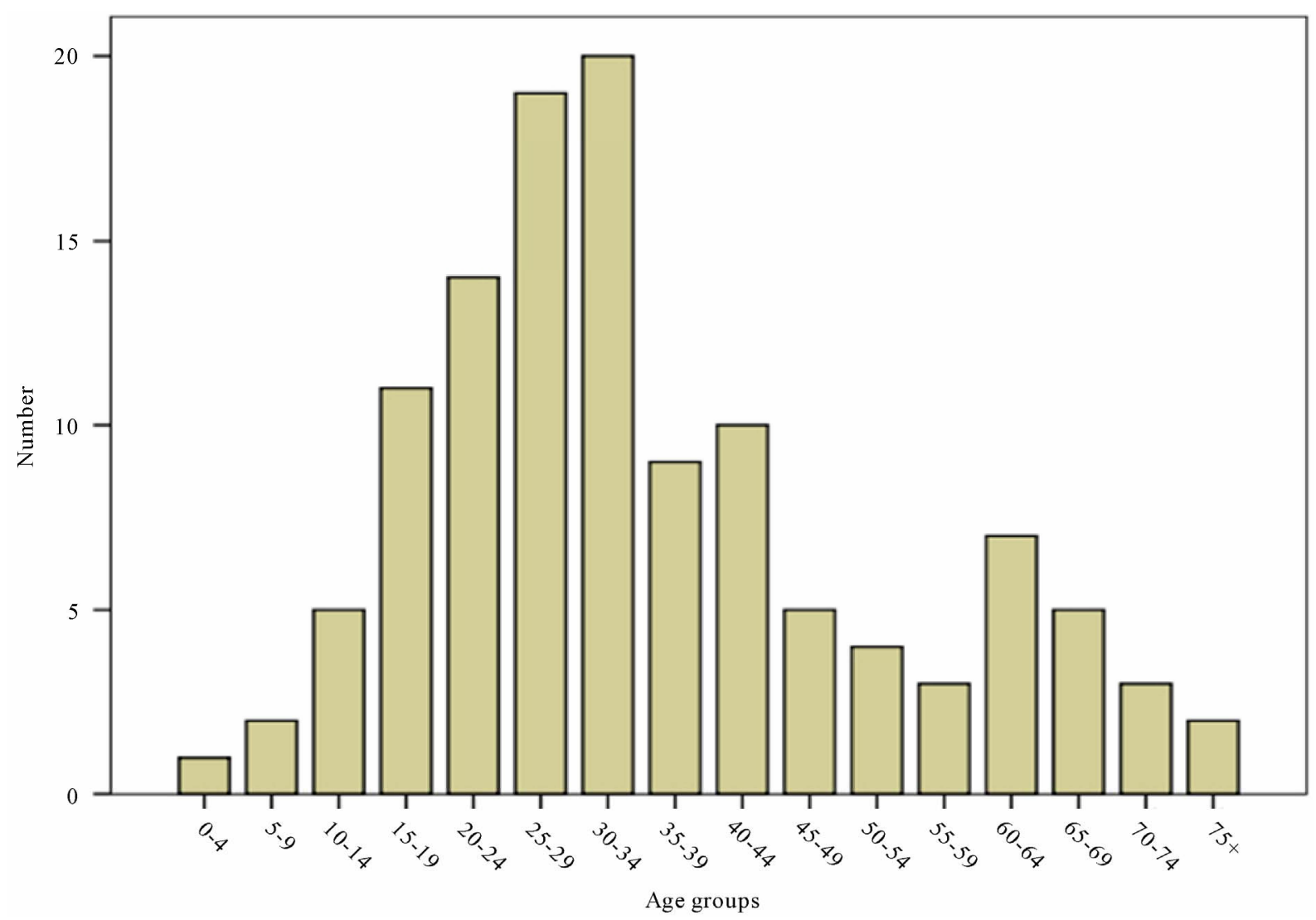

Figure 2. Number of traumatic cervical spine fracture for each age category.

Table 1. The distribution of cervical spine fractures.

\begin{tabular}{ccc}
\hline Spine Level & No. of Fractures & \% of All Fractures \\
\hline C1 & 12 & 10 \\
C2 & 25 & 20.8 \\
C3 & 14 & 11.7 \\
C4 & 12 & 10 \\
C5 & 18 & 15 \\
C6 & 12 & 10 \\
C7 & 9 & 7.5 \\
Multiple Fractures & 18 & 15 \\
Total & $\mathbf{1 2 0}$ & $\mathbf{1 0 0 . 0}$ \\
\hline
\end{tabular}

The dominant occupational category in upper cervical fracture was office workers (33.3\%), but in lower cervical, it was housewife (21.5\%) and for multiple fractures, it was construction workers (27.8\%).

The most common geographic location of a single cervical vertebral fracture was the Outer-city highways with 51 cases (50\%). The educational level of patients was as follows: $19.7 \%$ of the cases were illiterate, $29.1 \%$ completed primary school, 21.4\% middle school, 23.9\% high school and $5.9 \%$ were graduates of college or universities.

The most common mechanism of a single cervical vertebral fracture from $\mathrm{C} 1$ to $\mathrm{C} 7$ was motor vehicle crash (MVC) with 74 cases (72.5\%) but in multiple fractures, it was violence with 7 cases (38.9\%) (Table 2). The specific etiologies of MVC are presented in Table 3. Only $1.7 \%$ of the car occupants who were found to have TCSF had used seat belts and none of motorcycle riders who had TCSF had used helmets.

Accidental falls were the second most common mechanism of TCSF (21.7\%) and these fractures were most commonly due to falls of less than 4 meters (50\% of all fractures) (Table 4).

The mean of ISS was 13.3 and 13.9 in patients with fracture of upper and lower cervical spine fracture, respectively. The ISS was 10.3 in patients with multiple cervical vertebrae fractures. However, the difference in ISS among all patient groups was not statistically significant $(p=0.115)$.

Spinal cord and root injuries occurred in 34.9\% and $2.4 \%$ of TCSF, respectively. Neurological deficits included concussion and edema of cervical spinal cord in $13.3 \%$ of the patients, unspecified injuries of cervical 
Table 2. Characteristics of patients with traumatic cervical spine fractures.

\begin{tabular}{|c|c|c|c|c|c|}
\hline & & \multicolumn{3}{|c|}{ Anatomical location } & \multirow{2}{*}{ Total } \\
\hline & & Upper cervical (C1 - C2) & Lower cervical (C3 - C7) & Multiple & \\
\hline & & Number (\%) & Number (\%) & Number (\%) & Number (\%) \\
\hline \multirow{2}{*}{ Sex } & Male & $27(73)$ & $45(69.2)$ & $13(72.2)$ & $85(70.8)$ \\
\hline & Female & $10(27)$ & $20(30.8)$ & $5(27.8)$ & 35 (29.2) \\
\hline Age \pm SD & & $36.8 \pm 16.4$ & $37.4 \pm 17.8$ & $33.3 \pm 17.9$ & $36.6 \pm 17.2$ \\
\hline \multirow{4}{*}{ 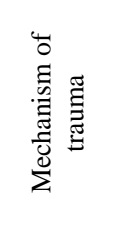 } & MVC* & $29(78.4)$ & $45(69.2)$ & $6(33.3)$ & $80(66.7)$ \\
\hline & Fall & $6(16.2)$ & $15(23.1)$ & $5(27.8)$ & $26(21.7)$ \\
\hline & Violence & $1(2.7)$ & $3(4.6)$ & 7 (38.9) & $11(9.2)$ \\
\hline & Others & $0(0)$ & $1(1.5)$ & $0(0)$ & $1(0.8)$ \\
\hline \multirow{6}{*}{ 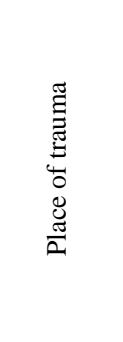 } & Home & $6(16.2)$ & 7 (11.1) & $6(33.3)$ & $19(16.1)$ \\
\hline & Outer -city highways & $23(62.2)$ & $28(44.4)$ & $4(22.2)$ & $55(46.6)$ \\
\hline & Street & $6(16.2)$ & $20(31.7)$ & $2(11.1)$ & $28(23.7)$ \\
\hline & At work & $0(0)$ & $4(6.3)$ & $5(27.8)$ & $9(7.6)$ \\
\hline & Sports or leisure facilities & $1(2.7)$ & $1(1.6)$ & $1(5.6)$ & $3(2.5)$ \\
\hline & Others & $1(2.7)$ & $3(4.8)$ & $0(0)$ & $4(3.3)$ \\
\hline \multirow{2}{*}{ Death } & Yes & $4(10.8)$ & $8(12.5)$ & $3(16.7)$ & $15(12.6)$ \\
\hline & No & 33 (89.2) & $56(87.5)$ & 15 (83.3) & 104 (87.4) \\
\hline
\end{tabular}

*Motor vehicle crash.

Table 3. Specific etiology of motor vehicle crash.

\begin{tabular}{ccccc}
\hline & & Anatomical location & Total \\
\cline { 2 - 4 } & Upper cervical & Lower cervical & Multiple & Number (\%) \\
\cline { 2 - 4 } & Number (\%) & Number (\%) & Number (\%) & $45(56.3)$ \\
Car passenger or driver & $16(55.2)$ & $26(57.8)$ & $3(50.0)$ & $11(13.8$ \\
Pedestrian & $2(6.9)$ & $9(20.0)$ & $0(0)$ & $17(21.3)$ \\
Motorcycle rider & $8(27.6)$ & $9(20.0)$ & $1(16.7)$ & $2(2.5)$ \\
Bicycle rider & $1(3.4)$ & $0(0)$ & $2(33.3)$ & $5(6.3)$ \\
Others & $2(6.9)$ & $1(2.2)$ & $\mathbf{6 ( 1 0 0 )}$ & $\mathbf{8 0}(\mathbf{1 0 0})$ \\
Total & $\mathbf{2 9 ( 1 0 0 )}$ & $\mathbf{4 5 ( 1 0 0 )}$ &
\end{tabular}

All data have been demonstrated as percentage of total.

spinal cord in $21.6 \%$, injury of the nerve root of cervical spine in $0.8 \%$ and the injuries of the peripheral nerve of neck in $1.6 \%$ (Figure 3 ).

None of patients with $\mathrm{C} 1$ fractures admitted into the hospital died. The percentages of in-hospital death in the upper, lower, and multiple cervical fractures were 10.8, 12.5 , and 16.7 , respectively. The mortality above rates difference was not statistically significant $(p=0.135)$.

\section{Discussion}

The aim of this investigation was to describe blunt TCSF in Iran. TCSF is an uncommon injury in Iran, as the incidence among all trauma patients was only $0.7 \%$. This is similar to the rates found in a recent literature review noting a TCSF rate of 1 to $3 \%$ of all trauma cases [3]. Claytor et al. reported 254 TCSF in 572 cervical spine 
Table 4. Specific mechanism of fall.

\begin{tabular}{|c|c|c|c|c|}
\hline & \multicolumn{3}{|c|}{ Anatomical location } & \multirow{2}{*}{ Total } \\
\hline & Upper cervical & Lower cervical & Multiple & \\
\hline & Number (\%) & Number (\%) & Number (\%) & Number (\%) \\
\hline$>4 \mathrm{~m}$ heights & $0(0)$ & $6(40.0)$ & $2(40.0)$ & $8(30.8)$ \\
\hline$<4 \mathrm{~m}$ heights & $4(66.7)$ & 8 (53.3) & $1(20.0)$ & $13(50.0)$ \\
\hline Stairs & $1(16.7)$ & $0(0)$ & $2(40.0)$ & $3(11.5)$ \\
\hline Falling to the ground & $1(16.7)$ & $6.7(15)$ & $0(0)$ & $7.7(26)$ \\
\hline Total & $6(100)$ & $15(100)$ & $5(100)$ & $26(100)$ \\
\hline
\end{tabular}

All data have been demonstrated as percentage of total.

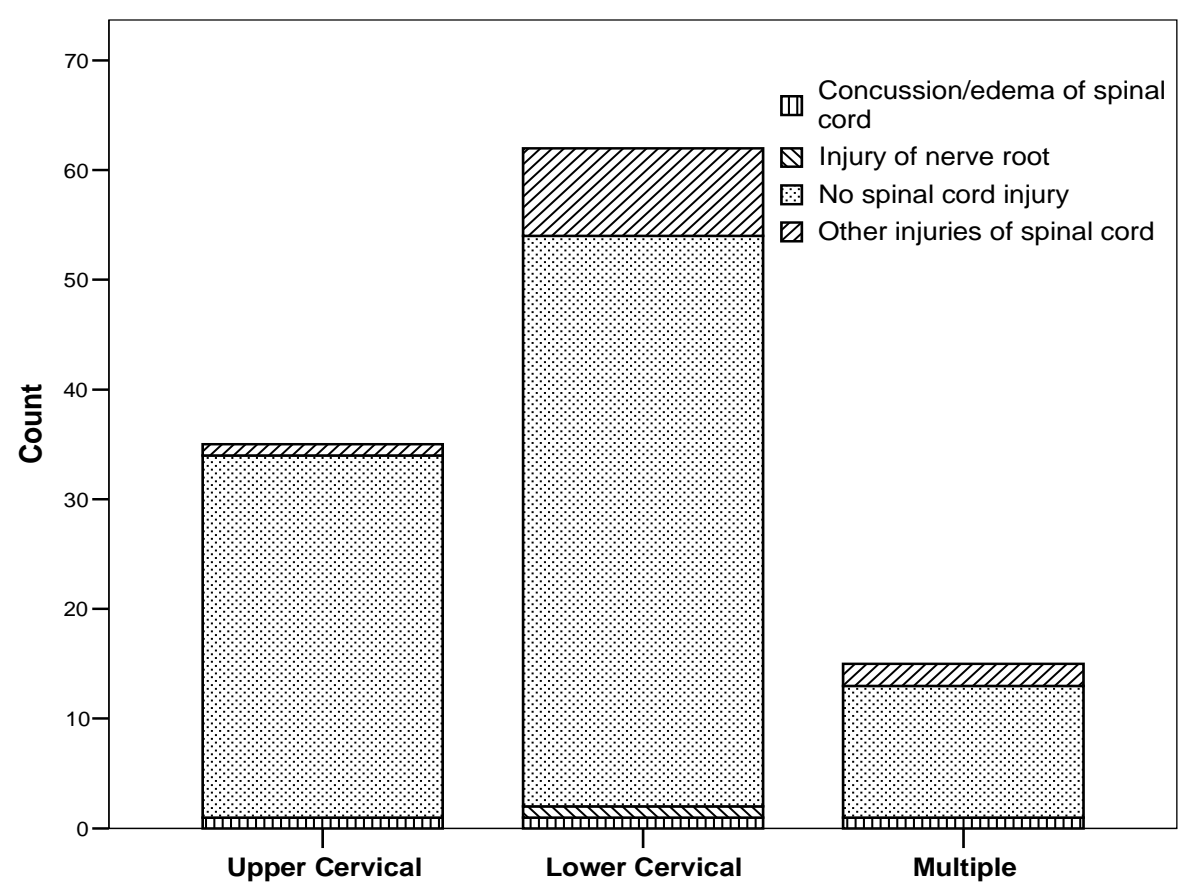

Figure 3. The number of spinal cord and root injuries in upper and lower of cervical spine fractures.

injuries (44.4\%) [15]. Thus, it seems that less than half of the patients with cervical spine injuries have an associated fracture. We showed that the overall incidence of TCSF among all spine fractured patients was $19.38 \%$. In $95 \%$ of the previous 38 reports, the incidence of cervical spine injury in all trauma patients varies from $1.5 \%$ to 9.0\% (Figure 4) [2]. In a meta-analysis gathering 65 studies with a total of 281,864 subjects, Milby et al. demonstrated that the overall incidence of cervical spine injury among all trauma patients was 3.7\% [2]. The lower incidence of TCSF among all trauma and spine fractured patients in our series could be due to the fact that we excluded any nonbony injury such as a ligamentous injury or a dislocation without a fracture.

We demonstrated the distribution of cervical spine fractures according to spine level, separately. Based on that, upper cervical spine fracture accounted for 30.8\% of TCSF, however a literature search notes that injury to the upper cervical spine accounts generally for 19 to $32.7 \%$ of all cervical spine injuries [3,4]. Fractures of C2 occurred most frequently in our study and this is the same as noted in the literature.

The majority of the patients were male (70.2\%) and the male/female ratio was 2.4; our data were supported by previous reported studies $[4,12,14,15]$. In addition, the male population, in all age groups, has a higher incidence of cervical fractures than females $[1,17]$. Of course Schoenfeld et al. surveyed a large multicultural military population, but our study was hospital-based [17].

The overall number of TCSF varies with age in a bi- 


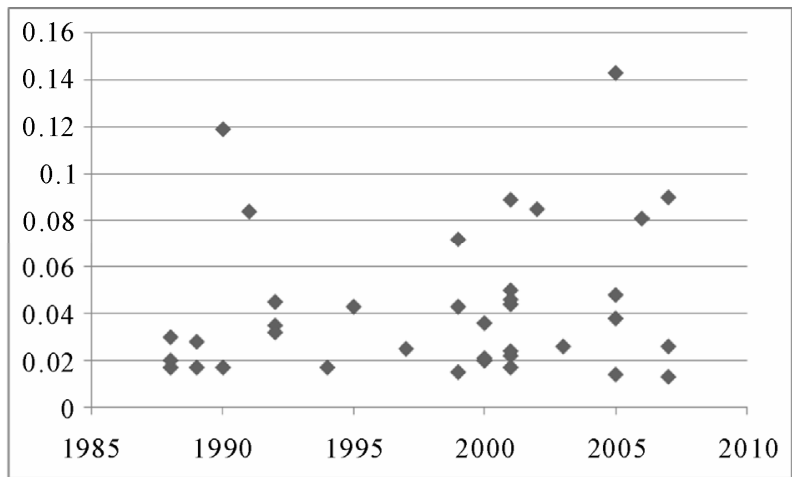

Figure 4. Incidence of cervical spine injury in trauma patients in different series.

modal fashion. This bimodal distribution was previously reported in the USA [15]. The first age peak was almost the same as seen in our study. Mean age for TCSF was 36.6 years in Iran and slightly older in the United States (42.3 and 43.8 years) $[8,18]$. The difference may be due to unsafe driving behavior in young adults and the younger population in Iran. The second peak in the USA was in individuals aged 65 to 85 years, which is older than our patients. This older peak may be due to osteoporotic fractures following falls or the longer length of life in developed countries.

The lower cervical spine is the most frequent location for spinal trauma. Our study did not show any age-dependent difference in region of TCSF. However, it has been shown that upper cervical spine injuries are the most frequent location for the population over 65 years of age [19].

We demonstrated the mechanisms of accident were coded according to the ICD-10. The most common mechanism of TCSF was MVC which has also been reported $[4,17,20]$. In some other studies, the most common mechanism was fall $[8,21]$. In Sweden, transportation related cervical fractures have dropped since 1991, leaving fall accidents as the sole largest cause of cervical trauma [1]. The most common mechanism of our patients was car occupants (56.6\%) in which just $4.4 \%$ used seat belt. In the $20.5 \%$ of MVC due to motorcycle accidents, no one used a safety helmet. Seat belt has been clearly shown to reduce overall mortality and morbidity in car accidents $[17,22,23]$ but no association has been shown between helmet use and the occurrence of cervical spine injuries in motor cycle collisions [24].

Spinal cord and root injuries occurred in 34.9\% and $2.4 \%$ of TCSF, respectively. Our results were almost the same as Sokolwski et al. which found that $31 \%$ of patients with upper cervical injuries and a higher percentage of lower cervical injuries had neurologic deficits on presentation [25]. In the study of Leucht et al., most of the neurological deficits occurred in response to cervical spine fractures, followed by thoracic and lumbar spine fractures and the highest number of complete motor and sensory neurological deficits was diagnosed in patients with cervical spine fractures [8].

The mean ISS was 13.3, 13.9 and 10.3 in upper, lower and multiple cervical spine fractures respectively, which is near to the median ISS of 14 reports in the literature [26]. In another study, the ISS was less than 16 in 8 patients, between 16 and 25 in 60 patients, and more than 26 in 53 patients [6].

The lowest percent of TCSF was at C7 (7.5\%) in Iran, however in the 808 cervical spine injuries in the NEXUS group study, there were $19.08 \%$ of injuries involving the C7 level [4]. This difference may be due to probable missed C7 cases following inadequately performed cervical radiography.

Based on the present study, the overall percentage of in-hospital death for TCSF was $12.6 \%$. Tolonen et al. showed that died patients following cervical spine injury comprised more than $10 \%$ of the causes of death in MVC [27], but Claytor et al. didn't reveal to rate of TCSF which lead to death [15].

This study has limitations that the readers should bear in mind. Providing further information on the anatomic distribution, location, different parts of each vertebra fracture, such as odontoid, dislocations by cervical spine level and radiographic findings would be helpful.

The most common mechanism for TCSF was MVC. The young in all populations appear to be most affected which unfortunately is the productive labor force in Iran, a country more prone to TCSF.

\section{Acknowledgement}

The database was provided by the Sina Trauma and Surgery Research Center of Tehran University Medical Sciences. The authors thank Mrs. Bita Pourmand for her edit of the manuscript.

\section{References}

[1] K. Brolin and H. von Holst, "Cervical Injuries in Sweden, a National Survey of Patient Data from 1987 to 1999," Injury Control and Safety Promotion, Vol. 9, No. 1, 2002, pp. 40-52. doi:10.1076/icsp.9.1.40.3318

[2] A. H. Milby, C. H. Halpern, W. Guo and S. C. Stein, "Prevalence of Cervical Spinal Injury in Trauma," Neurosurg Focus, Vol. 25, No. 5, 2008, p. E10. doi:10.3171/FOC.2008.25.11.E10

[3] H. Pratt, E. Davies and L. King, "Traumatic Injuries of the c1/c2 Complex: Computed Tomographic Imaging Appearances," Current Problems in Diagnostic Radiology, Vol. 37, No. 1, 2008, pp. 26-38. doi:10.1067/j.cpradiol.2007.07.001 
[4] W. Goldberg, C. Mueller, E. Panacek, S. Tigges, J. R. Hoffman and W. R. Mower, "Distribution and Patterns of Blunt Traumatic Cervical Spine Injury,” Annals Emergency Medicine, Vol. 38, No. 1, 2001, pp. 17-21. doi:10.1067/mem.2001.116150

[5] L. D. Bob, C. C. Blackmore, F. A. Mann and F. M. Lomoschitz, "Cervical Spine Fractures in Patients 65 Years and Older: A Clinical Predication Rule for Blunt Trauma,” Radiology, Vol. 234, 2005, pp. 143-149. doi:10.1148/radiol.2341031692

[6] C. Olerud, S. Andersson, B. Svensson and J. Bring, “Cervical Spine Fractures in the Elderly: Factors Influencing Survival in 65 Cases,” Acta Orthopeadica, Vol. 70, No. 5, 1999, pp. 509-513. doi:10.3109/17453679909000990

[7] P. Heidari, M. R. Zarei, M. R. Rasouli, R. V. Alexander and V. Rahimi-Movaghar, "Spinal Fractures Resulting from Traumatic Injuries," Chinese Journal of Traumatology, Vol. 13, No. 1, 2010, pp. 3-9.

[8] P. Leucht, K. Fischer, G. Muhr and E. J. Muller, "Epidemiology of Traumatic Spine Fractures,” Injury, Vol. 40, No. 2, 2009, pp. 166-172. doi:10.1016/j.injury.2008.06.040

[9] F. H. Geisler, W. P. Coleman, G. Grieco and D. Poonian, "Recruitment and Early Treatment in a Multicenter Study of Acute Spinal Cord Injury,” Spine, Vol. 26, No. 245, 2001, pp. S58-S67. doi:10.1097/00007632-200112151-00013

[10] S. J. Rizzolo, A. R. Vaccaro and J. M. Cotler, "Cervical Spine Trauma,” Spine, Vol. 19, No. 20, 1994, pp. 22882298.

[11] D. M. Banit, G. Grau and J. R. Fisher, "Evaluation of the Acute Cervical Spine: A Management Algorithm,” Journal of Trauma-Injury Infection \& Critical Care, Vol. 49, No. 3, 2000, pp. 450-456. doi:10.1097/00005373-200009000-00011

[12] D. C. Reid, R. Henderson, L. Sahoe and J. D. Miller, "Etiology and Clinical Course of Missed Spinal Fractures," Journal of Trauma-Injury Infection \& Critical Care, Vol. 27, No. 9, 1987, pp. 980-986. doi:10.1097/00005373-198709000-00005

[13] H. Ersmark and P. Lowenhielm, "Factors Influencing the Outcome of Cervical Spine Injuries," Journal of TraumaInjury Infection \& Critical Care, Vol. 28, No. 3, 1988, pp. 407-410. doi:10.1097/00005373-198803000-00020

[14] O. P. Sharma, M. F. Oswanski, J. S. Yazdi, S. Jindal and M. Taylor, "Assessment for Additional Spinal Trauma in Patients with Cervical Spine Injury,” The American Surgeon, Vol. 73, No. 1, 2007, pp. 70-74.

[15] B. Claytor, P. A. MacLennan, G. McGwin Jr, L. W. Rue 3rd and J. S. Kirkpatrick, "Cervical Spine Injury and Restraint System Use in Motor Vehicle Collisions,” Spine, Vol. 29, No. 4, 2004, pp. 386-389.

\section{doi:10.1097/01.BRS.0000102491.46568.B3}

[16] M. Stevenson, M. Segui-Gomez, I. Lescohier, C. Di Scala and G. McDonald-Smith, "An Overview of the Injury Severity Score and the New Injury Severity Score," Injury Prevention, Vol. 7, No. 1, 2001, pp. 10-13.

[17] A. J. Schoenfeld, B. Sielski, K. P. Rivera, J. O. Bader and M. B. Harris, "Epidemiology of Cervical Spine Fractures in the US Military,” Spine, 2011, In Press.

[18] D. W. Lowery, M. M. Wald, B. J. Browne, S. Tigges, J. R. Hoffman and W. R. Mower, "Epidemiology of Cervical Spine Injury Victims,” Annals Emergency Medicine, Vol. 38, No. 1, 2001, pp. 12-16. doi:10.1067/mem.2001.116149

[19] K. Brolin, "Neck Injuries among the Elderly in Sweden," Injury Control and Safety Promotion, Vol. 10, No. 3, 2003, pp. 155-164. doi:10.1076/icsp.10.3.155.14558

[20] L. T. Holly, D. F. Kelly, G. T. Counelis, T. Blinmant, D. L. McArthur and H. G. Cryer, "Cervical Spine Trauma Associated with Moderate and Severe Head Injury: Incidence, Risk Factors, and Injury Characteristics,” Journal of Neurosurgery, Vol. 96, No. 3, 2002, pp. 285-291.

[21] T. J. Birney and E. N. Hanley Jr, "Traumatic Cervical Spine Injuries in Childhood and Adolescence," Spine, Vol. 14, No. 12, 1989, pp. 1277-1282. doi:10.1097/00007632-198912000-00001

[22] L. Evans, "Restraint Effectiveness, Occupant Ejection from Cars, and Fatality Reductions,” Accident Analysis \& Prevention, Vol. 22, No. 2, 1990, pp. 167-175. doi:10.1016/0001-4575(90)90067-U

[23] P. L. Zador and M. A. Ciccone, “Automobile Driver Fatalities in Frontal Impacts: Air Bags Compared with Manual Belts,” American Journal of Public Health, Vol. 83, No. 5, 1993, pp. 661-666. doi:10.2105/AJPH.83.5.661

[24] A. Moskal, J. L. Martin and B. Laumon, "Helmet Use and the Risk of Neck or Cervical Spine Injury among Users of Motorized Two-Wheel Vehicles," Injury Prevention, Vol. 14, No. 4, 2008, pp. 238-244. doi:10.1136/ip.2007.018093

[25] M. J. Sokolowski, A. P. Jackson, M. H. Haak, P. R. Meyer Jr and M. Szewczyk Sokolowski, "Acute Outcomes of Cervical Spine Injuries in the Elderly: Atlantaxial Vs Subaxial Injuries,” The Journal of Spinal Cord Medicine, Vol. 30, No. 3, 2007, pp. 238-242.

[26] A. Polk-Williams, B. G. Carr, T. A. Blinman, P. T. Masiakos, D. J. Wiebe and M. L. Nance, "Cervical Spine Injury in Young Children: A National Trauma Data Bank Review," Journal of Pediatric Surgery, Vol. 43, No. 9, 2008, pp. 1718-1721. doi:10.1016/j.jpedsurg.2008.06.002

[27] J. Tolonen, S. Santavirta, O. Kiviluoto, and C. Lindqvist, "Fatal Cervical Spinal Injuries in Road Traffic Accidents,” Injury, Vol. 17, No. 3, 1986, pp. 154-158. doi:10.1016/0020-1383(86)90321-9 